\title{
DO DIREITO À CIDADE AO DIREITO À ACESSIBILIDADE: ANÁLISE DA ACESSIBILIDADE EM LOCAIS DE SERVIÇOS E LAZER NO CENTRO DE FLORIANÓPOLIS/SC
}

Tamara de Castro Régis ${ }^{1}$ Ruth Emilia Nogueira ${ }^{2}$

Resumo: Este artigo tem como objetivo realizar uma análise da acessibilidade no Centro de Florianópolis/SC, quanto à presença de infraestrutura que facilite a mobilidade de pessoas com deficiência, e seu acesso aos pontos turísticos e serviços. Como referência principal utilizou-se a obra "Direito à Cidade" de Henri Lefebvre (1991), e sob a ótica deste, analisaram-se as legislações, que remetem à acessibilidade. Como procedimentos metodológicos foram realizadas saídas de campo pelos principais pontos turísticos e de serviços da cidade. Nestas, avaliou-se a existência de estruturas de acessibilidade que propiciem às pessoas com deficiência de usufruir da cidade com autonomia. Os resultados mostram um levantamento das infraestruturas existentes ou inexistentes, que dão ou possam vir a dar emancipação de mobilidade e acesso à informação aos cidadãos com impedimentos físicos, auditivos e visuais. São apontadas também novas propostas e/ou possibilidades de melhorias dessas infraestruturas.

Palavras-chave: Direito à Cidade. Acessibilidade. Pessoas com Deficiência. Inclusão Social. Direitos Humanos.

\section{THE RIGHT TO THE CITY TO THE RIGHT TO ACCESSIBILITY: ANALYSIS OF ACCESSIBILITY IN PLACES OF SERVICES AND LEISURES IN THE CENTER OF FLORIANÓPOLIS/ SC}

Abstract: This article has with objectives make the analisys of accessibility in Center of Florianópolis/SC, about mobility of desabled people and accessibility of places tourist and the services. For that it took as main references the text of Henri Lefebvre the "right the city", and from the perspective of it, was analyzed the laws that refer to accessibility in the city. As methodological procedures we did a field work for the main tourist attractions in the city and the places of services, they were chosen considering the access of these citizens so that they can enjoy the city with autonomy as people without disabilities. As result presents a survey of existing infrastructures or non-existent structures that would provide empowerment and information for the people with physical disabilities, hearing and visual thereof. New proposals and / or possibilities for improvement in the existing infrastructure are also mentioned.

Keywords: Right the City. Accessibility. People with disabilities. Social Inclusion. Human Rights.

\footnotetext{
${ }^{1}$ Universidade do Estado de Santa Catarina, Departamento de Geografia, Florianópolis, Brasil, tamara.regis@hotmail.com, https://orcid.org/0000-0003-4116-3132

${ }^{2}$ Universidade Federal de Santa Catarina, Departamento de Geociências, Florianópolis, Brasil, ruthenogueira@gmail.com, https://orcid.org/0000-0002-8119-3857
} 


\section{DEL DERECHO A LA CIUDAD AL DERECHO A LA ACCESIBILIDAD: ANÁLISIS DE ACCESIBILIDAD EN LUGARES DE SERVICIOS Y OCIO EN EL CENTRO DE FLORIANÓPOLIS / SC}

Resumen: Este artículo tiene como objetivo realizar un análisis de accesibilidad en el Centro de Florianópolis / SC, en cuanto a la presencia de infraestructura que facilite la movilidad de las personas con discapacidad, y su acceso a lugares de interés y servicios. Como referencia principal se utilizó la obra "Derecho a la ciudad" de Henri Lefebvre (1991), y desde la perspectiva de la misma se analizó la legislación, que se refiere a la accesibilidad. Como procedimientos metodológicos se realizaron salidas de campo a los principales puntos turísticos y de servicios de la ciudad. En estos, se evaluó la existencia de estructuras de accesibilidad que permitan a las personas con discapacidad disfrutar de la ciudad con autonomía. Los resultados muestran un relevamiento de las infraestructuras existentes 0 inexistentes, que dan o pueden dar emancipación de la movilidad y acceso a la información a los ciudadanos con discapacidad física, auditiva y visual. También se señalan nuevas propuestas y / o posibilidades de mejora de estas infraestructuras.

Palabras clave: Derecho a la Ciudad. Accesibilidad. Personas con deficiencia. Inclusión social. Derechos humanos.

\section{Introdução}

O direito à cidade é uma questão de debates ao longo dos anos, principalmente no que tange a apropriação dos espaços públicos pela sociedade. Esta reivindicação advém das ideias de Henri Lefebvre (1991), que em seu livro intitulado "O direito à Cidade3" defende o direito à apropriação do espaço urbano e a possibilidade de os cidadãos participarem, com qualidade, da vida da cidade.

A partir dessas ideias buscou-se dialogar acerca do direito à cidade para uma parcela restrita da população: as pessoas com deficiência. Por pessoas com deficiência, considerou-se o exposto na Lei Brasileira de Inclusão da Pessoa com Deficiência (Estatuto da Pessoa com Deficiência). Nesta, considera-se pessoa com deficiência aquela que tem impedimento de longo prazo de natureza física, mental, intelectual ou sensorial, o qual, em interação com uma ou mais barreiras, pode obstruir sua participação plena e efetiva na sociedade em igualdade de condições com as demais pessoas (BRASIL, 2015).

Embora a acessibilidade seja uma questão discutida internacionalmente, as cidades moldadas à luz de um planejamento urbano ineficiente apresentam diversos

\footnotetext{
${ }^{3}$ O livro "O direito à Cidade ${ }^{3 "}$ ou "Le droit à la ville" teve sua primeira edição publicada em 1968.
} 
problemas para serem acessadas por todos, fato que merece destaque por limitar os direitos de vida plena dos cidadãos.

Para as pessoas com deficiência, o direito à cidade está intrínseco ao direito à acessibilidade. A acessibilidade é a possibilidade e condição de alcance para utilização, com segurança e autonomia, de espaços, mobiliários, equipamentos urbanos, edificações, transportes, informação e comunicação, inclusive seus sistemas e tecnologias, bem como de outros serviços e instalações abertos ao público, de uso público ou privado de uso coletivo, tanto na zona urbana como na rural, por pessoa com deficiência ou com mobilidade reduzida (BRASIL, 2015).

A acessibilidade constitui-se como um direito das pessoas com deficiência, destacando-se nas legislações como um direito que possibilita às pessoas com deficiência viver de forma independente, participar plenamente de todos os aspectos da vida, exercer seus direitos de cidadania e de participação social. Para efetivar-se o direito à acessibilidade, deverão ser tomadas as medidas apropriadas para assegurar 0 acesso das pessoas com deficiência, em igualdade de oportunidades com as demais pessoas. (BRASIL, 2009, 2015).

Considerando a relevância do direito à acessibilidade para as pessoas com deficiência, e a necessidade de problematizar que a inobservância deste direito impede estes cidadãos de participarem da vida da cidade, trazemos como objetivo neste artigo realizar uma análise quanto à presença de infraestrutura que facilite às pessoas com deficiência o acesso aos pontos turísticos e serviços no Centro da cidade de Florianópolis. Entre as distintas formas de impedimentos apresentadas nas legislações, escolheu-se analisar a acessibilidade para pessoas com impedimentos sensoriais: cegos e surdos e, de natureza física que se manifestam por meio da mobilidade reduzida, sendo que esta pode ser permanente ou temporária, incluindo idoso, gestante, lactante, pessoa com criança de colo e obeso (BRASIL, 2015).

Neste estudo, empregou-se como procedimentos metodológicos: a consulta bibliográfica nas legislações advindas da Convenção sobre os Direitos das Pessoas com Deficiência (ONU, 2006) e a atividade de campo, para verificar como as legislações de acessibilidade materializam-se no espaço. O campo de pesquisa foi o Centro da cidade de Florianópolis. Por meio de visitas e entrevistas verificou-se as estruturas de serviços e lazer procurando identificar se estas possuem os parâmetros de acessibilidade necessários para propiciar o acesso com autonomia às pessoas com deficiência. Para a escolha dos locais analisados, considerou-se dois 
critérios: locais de serviços e locais de turismo ou lazer. Estes foram selecionados, considerando a oferta de serviços para a vida autônoma as pessoas com deficiência, seus direitos de cidadania e de participação social e ponderando a relevância histórica. Os locais visitados podem ser observados na Figura 1.

Figura 1- Locais visitados no Centro de Florianópolis.

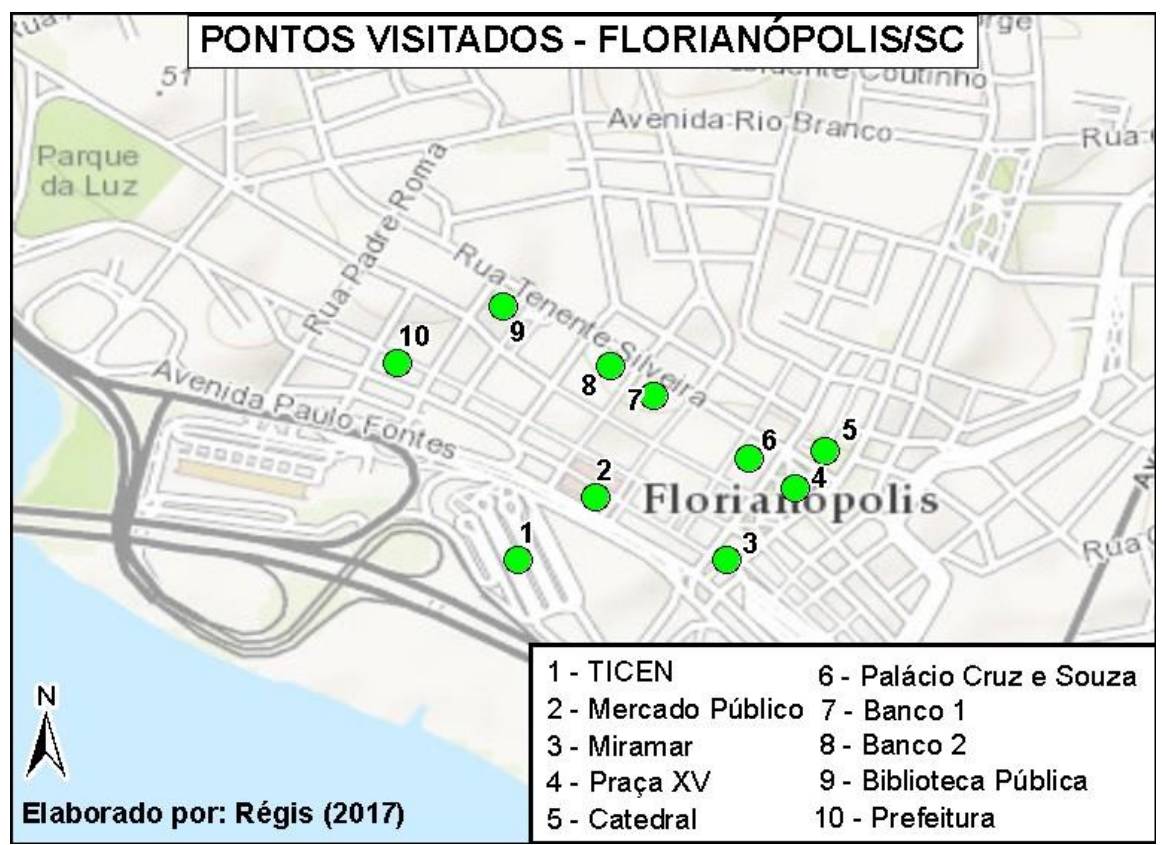

Fonte: Régis, 2020. Descrição da imagem: mapa de ruas do Centro de Florianópolis ao fundo com destaque de um ponto verde e um número correspondente a cada local. 1. Terminal de ônibus urbano (TICEN), 2. Mercado Público de Florianópolis, 3. Miramar, 4. Praça XV de Novembro, 5. Catedral Metropolitana, 6. Palácio Cruz e Souza, 7 e 8. duas instituições bancárias, 9. Biblioteca Pública e 10. Prefeitura Municipal de Florianópolis.

Com base nos critérios definidos, foram visitados: o Terminal Urbano de Florianópolis (TICEN), a Prefeitura Municipal de Florianópolis, a Biblioteca Pública do Estado de Santa Catarina, Instituições Bancárias, o Palácio Cruz e Souza, a Catedral Metropolitana de Florianópolis, a Praça XV de Novembro e o Miramar, a Secretaria Municipal de Mobilidade Urbana (SMMU) responsável pelo serviço de transporte urbano no município e o Mercado Público de Florianópolis.

A análise foi realizada com base nas estruturas promotoras de acessibilidade apresentadas na legislação. Considerou-se, a facilidade de mobilidade sem tutela que abarca a existência de calçadas, rampas e elevadores para cadeirantes, assim como de piso tátil e de alerta para pessoas com deficiência visual; a disponibilidade de alerta sonoro nas sinaleiras para pessoas com deficiência visual e, nos locais de serviço a adoção de painéis com informações visuais e a disponibilidade de informação sonora. Também foi analisada a presença/ausência de mapas adaptados para mobilidade no interior das estruturas. Nos locais de turismo ou lazer, 
além da acessibilidade quanto à mobilidade, verificou-se a existência de informações turísticas adaptadas às pessoas com deficiência e a presença de intérpretes de LIBRAS $^{4}$.

Por fim, os dados obtidos foram analisados à luz do referencial teórico, diagnosticando se as estruturas estão de acordo com as legislações e apontando as adaptações razoáveis para que se adequem.

\section{O direito à cidade e a acessibilidade}

O Direito à Cidade, de acordo com Carta Mundial pelo Direito à Cidade (2006), é entendido como o usufruto equitativo das cidades considerando os princípios de sustentabilidade, democracia e justiça social. Este configura-se como sinônimo de justiça no acesso aos direitos que promovem uma vida plena, de forma que todas as pessoas possam desfrutar das benfeitorias disponíveis no meio urbano. É um direito coletivo dos habitantes das cidades, em especial dos grupos vulneráveis e desfavorecidos, que lhes confere legitimidade de ação e organização, baseado em seus usos e costumes, com o objetivo de alcançar o pleno exercício do direito à livre autodeterminação e a um padrão de vida adequado.

O Direito à Cidade é interdependente a todos os direitos humanos internacionalmente reconhecidos. Para Lefebvre (1991) o direito à cidade abrange aspectos mais complexos do que o simples acesso a cidade, o autor defende que:

$\mathrm{O}$ direito à cidade se manifesta como forma superior: direito à liberdade, à individualização na socialização, ao habitat e ao habitar. $\mathrm{O}$ direito à obra (à atividade participante) e o direito à apropriação (bem distinto do direito à propriedade) estão envolvidos no direito à cidade (LEFEBVRE, 1991, p.155).

Entre as reflexões expostas na obra, destaca-se o direito ao habitar. Para Lefebvre (1991) o habitar é participar da vida social de uma comunidade, aldeia ou cidade, portanto é necessário ter contato com outros citadinos. Nesse caso pergunta-se: Como pessoas com deficiência irão habitar em uma sociedade onde o acesso à vida urbana é repleta de barreiras que os impedem de uma participação plena? Viver, ou seja, habitar a cidade se constitui um constante desafio para essas pessoas, que enfrentam riscos à integridade física, na tentativa de exercer o direito constitucional de ir e vir.

\footnotetext{
${ }^{4}$ A Língua Brasileira de Sinais é a segunda língua oficial do Brasil sendo utilizada principalmente por pessoas surdas como forma de comunicação (BRASIL, 2015).
} 
Outro ponto abordado pelo autor, que vem sendo debatido na atualidade, é a participação efetiva dos citadinos na construção da cidade. Esta é uma demanda reivindicada pelo Movimento das Pessoas com Deficiência, e um dos princípios gerais da Convenção sobre os Direitos das Pessoas com Deficiência (ONU, 2006). Sendo que este documento se configura como um marco legislatório na luta pelos direitos das pessoas com deficiência e preconiza uma série de legislações no Brasil, como: o Decreto Legislativo n 6.949, de 25 de agosto de 2009 (BRASIL, 2009), a Lei Brasileira de Inclusão da Pessoa com Deficiência (BRASIL, 2015).

Estas legislações, apontam a participação como um dos princípios gerais para a plena e efetiva inclusão na sociedade, assim como o respeito pela diferença, a não discriminação, a aceitação das pessoas com deficiência como parte da diversidade humana e da humanidade, igualdade de oportunidades e a acessibilidade. Sendo que a participação pode ser efetivada nas escolhas, na adaptação das estruturas e na construção de uma cidade mais acessível para todos (BRASIL, 2009; 2015).

Todavia, o planejamento urbano relegado a especialistas e técnicos, já na época da publicação da obra de Lefebvre, é um fator que mina a participação tão defendida por inúmeros estudiosos do planejamento urbano contemporâneo. 0 direito à participação evocado por Lefebvre (1991) refere-se à construção da cidade ao direito de intervir sobre as suas estruturas.

Ainda na mesma obra, o autor, defende o direito à apropriação (que nada tem em comum com o direito à propriedade), o qual também é uma das reivindicações nas lutas das pessoas com deficiência. É o direito de se apoderar e usufruir dos espaços de uso comum da cidade, é poder passear com autonomia por uma praça, admirar uma exposição artística, poder usufruir de artefatos culturais que são negados às pessoas com deficiência, em virtude da existência de barreiras.

Por barreiras, o Estatuto da Pessoa com Deficiência considera: os entraves, obstáculos, atitudes ou comportamentos que limitem ou impeçam a participação social da pessoa, bem como o exercício de seus direitos à acessibilidade, à liberdade de movimento e de expressão, à comunicação, ao acesso à informação, à compreensão, à circulação com segurança, entre outros. Podendo ser classificadas em: barreiras urbanísticas; barreiras arquitetônicas; barreiras nos transportes; barreiras nas comunicações e na informação; barreiras atitudinais; barreiras tecnológicas. (BRASIL, 2015)

As diversas formas de barreiras, enfrentadas pelas pessoas com deficiência, originam-se quase que em sua totalidade pela não observação do Desenho 
Universal. Este configura-se na concepção de produtos, ambientes, programas e serviços a serem usados por todas as pessoas, sem necessidade de adaptação ou de projeto específico, incluindo os recursos de tecnologia assistiva que são produtos que objetivam promover a funcionalidade, relacionada à atividade e à participação da pessoa com deficiência ou com mobilidade reduzida, visando à sua autonomia, independência, qualidade de vida e inclusão social (BRASIL, 2015).

Relacionado ao direito à cidade, o capítulo IX Estatuto da Pessoa com Deficiência aborda o Direito à Cultura, ao Esporte, ao Turismo e ao Lazer. Destacase que estes direitos se efetivam através da igualdade de oportunidades com as demais pessoas. Conforme o Art. 42, a garantia deste direito se dará pela oferta de bens culturais em formato acessível, programas de televisão, cinema, teatro, a monumentos e locais de importância cultural e a espaços que ofereçam serviços ou eventos culturais e esportivos. Devendo o poder público adotar soluções destinadas à eliminação, à redução ou à superação de barreiras para a promoção do acesso a todo patrimônio cultural, observadas as normas de acessibilidade, ambientais e de proteção do patrimônio histórico e artístico nacional.

A observância dos critérios de acessibilidade, a superação das barreiras, o planejamento urbano realizado nos moldes do Desenho Universal, empregando recursos de tecnologia assistiva, considerando a participação das pessoas com deficiência, é imperativo para a consolidação do direito à cidade, à vida urbana, aos direitos básicos e essenciais do ser humano.

\section{As estruturas de promoção à acessibilidade}

Ao longo das décadas de 1980 e 1990 as discussões de acessibilidade passam da eliminação de barreiras arquitetônicas a um sentido mais amplo. Através do reconhecimento de que grande parte da população mundial não se ajusta ao modelo no qual os espaços públicos e edificações são projetados e visando atender a maior gama possível de pessoas, insere-se nos debates a discussão do Desenho Universal (ALVAREZ; CAMISÃO, 2014).

Embora haja um histórico de discussões acerca da acessibilidade, Alvarez e Camisão (2014) apontam que, a maior parte das áreas urbanas edificadas nas grandes cidades latino-americanas permanecem inacessíveis, sendo que muitas das cidades ainda não iniciaram seu processo de adequação. Como justificativas a esta realidade, os autores destacam: as dificuldades nas ações pró-acessibilidade que advém da carência de formação dos profissionais de arquitetura e engenharia, as 
dificuldades são ampliadas pela legislação heterogênea, pela baixa difusão das normas técnicas, assim como o cumprimento facultativo destas e a falta de fiscalização.

O Brasil não foge ao exposto pelos autores, há uma gama de legislações e normatizações que visam garantir a acessibilidade. Entretanto, nem sempre o papel de cada uma destas legislações está claro. Neste sentido, cabe explicitar que as leis federais como o Decreto Legislativo $n^{\circ}$ 6.949, de 25 de agosto de 2009 (BRASIL, 2009), a Lei Brasileira de Inclusão da Pessoa com Deficiência (BRASIL, 2015), apontam que a União deve garantir o direito das pessoas com deficiência e instituir as diretrizes para a inclusão de regras de acessibilidade, todavia não há discriminação de como deve ser implantado estas estruturas (BRASIL, 2009; 2015).

As leis municipais, Lei ํo 7801 , de 30 de dezembro de 2008 e a Lei complementar no 590, de 06 de dezembro de 2016, normatizam como será aplicada a lei no município de Florianópolis. Estas leis estabelecem que os critérios básicos à promoção da acessibilidade devem seguir à norma NBR 9050/2015 e estar em consonância com as leis anteriores.

Nesta pesquisa, limitou-se à análise das estruturas de acessibilidade voltadas à mobilidade e enfrentamento das barreiras informacionais e comunicacionais. Para apresentar estas estruturas, utilizou-se como fonte de pesquisa a norma NBR 9050/2015 - da Associação Brasileira de Normas Técnicas (ABNT) e o Caderno de Planejamento e Projetos Urbanos de Florianópolis desenvolvido pelo Instituto de Planejamento Urbano de Florianópolis (IPUF) que apresenta de forma didática o exposto na norma técnica.

A normalização técnica das estruturas de acessibilidade é realizada pela ABNT, através da NBR 9050. Esta norma técnica foi criada em 1983 e teve sua primeira revisão em 1994, a segunda em 2004 e a terceira em 2015. A atualização da norma advém da necessidade de aprimorar, esclarecer e complementar a norma anterior.

Figueiredo (2015) destaca que, a atualização da NBR 9050 em 2015, além de apresentar informações detalhadas e precisas para projetar e melhorar o acesso e uso dos espaços e mobiliários, ampliou-se o conceito de "Desenho Universal" empregando o exposto na Lei Brasileira de Inclusão da Pessoa com Deficiência. No campo da comunicação, introduziu-se o "princípio dos dois sentidos" (A informação deve ocorrer através do uso de no mínimo dois sentidos: visual e tátil ou visual e sonoro). A NBR 9050/2015 ampliou as orientações e detalhou o conceito de 
"mobiliário urbano": sendo este o conjunto de objetos existentes nas vias e nos espaços públicos, superpostos ou adicionados aos elementos de urbanização ou de edificação. Modificou as orientações para adaptação de edificações e equipamentos urbanos existentes, em especial as orientações para rotas acessíveis, sendo que agora todas as entradas devem ser acessíveis, caso não seja possível, deve ser adaptado o maior número de acessos possíveis.

Para se acessar a cidade de forma autônoma, destaca-se a mobilidade. Para a mobilidade urbana de pessoas com deficiência a NBR-9050/15, aponta alguns fatores a serem considerados, tais como: a existência de rotas acessíveis e contínuas que permitam aos usuários o acesso seguro a diferentes locais dentro da cidade.

Este acesso seguro predispõe a existência de calçadas com no mínimo 1,20 $\mathrm{m}$ de largura nas áreas de passeio e declividade transversal máxima de 3\%, sendo que elas devem ser projetadas sem obstáculos e devem conter piso tátil. O piso tátil de alerta deve ser colocado perpendicularmente ao sentido de deslocamento, em cor preta (no município de Florianópolis) e texturas contrastantes com o resto do piso adjacente, mostrando às pessoas com deficiência visual o rebaixamento de calçadas, obstáculos sobre o passeio, portas de elevadores, desníveis em vãos, início e término de escadas e rampas. O piso tátil direcional deve ser implantado próximo ao meio das calçadas, onde se tem maior segurança para circulação e em uma área livre de obstáculos e utilizado no sentido de deslocamento para indicar o caminho a ser percorrido, devendo ser contrastante em cor e textura com as áreas do entorno (ABNT-NBR-9050/15; FLORIANÓPOLIS, 2020).

As rampas são estruturas que promovem a acessibilidade de pessoas com mobilidade reduzida. Estas constituem-se em inclinação da superfície de piso, longitudinal ao sentido de caminhamento, com declividade igual ou superior a $5 \%$. A NBR-9050/15 especifica-se ainda como implantar calçadas rebaixadas, que são rampas construídas ou implantadas na calçada e entradas, destinadas a promoverem a concordância de nível entre a calçada e a rua (ABNT-NBR-9050/15; FLORIANÓPOLIS, 2020).

A acessibilidade na mobilidade urbana, engloba os serviços de transportes e suas estruturas. Regulamenta a existência de ônibus adaptados, orienta a preservação da faixa livre na calçada para deslocamento e circulação de pedestres e garante o espaço para pessoas em cadeiras de rodas, quando houver assentos fixos nos terminais e pontos de ônibus de transporte público (ABNT-NBR-9050/15). 
Entre os critérios de acessibilidade, salienta-se a comunicação. A Lei Brasileira de Inclusão da Pessoa com Deficiência considera, a comunicação como toda forma de interação dos cidadãos. Abrange, entre outras opções, as línguas, inclusive a LIBRAS, a visualização de textos, o Braille, o sistema de sinalização ou de comunicação tátil, os caracteres ampliados, os dispositivos multimídia, assim como a linguagem simples, escrita e oral, os sistemas auditivos e os meios de voz digitalizados e os modos, meios e formatos aumentativos e alternativos de comunicação, incluindo as tecnologias da informação e das comunicações. A NBR 9060/2015 aponta que, a comunicação pode ser em linguagem visual, tátil ou sonora e fundamentalmente, tem a capacidade de proporcionar inteligibilidade.

A NBR9060/2015, em seu Anexo A, apresenta como um dos princípios do desenho universal a existência de informação de fácil percepção. Essa característica do ambiente ou elemento espacial faz com que seja redundante e legível quanto a apresentações de informações vitais. Essas informações devem se apresentar em diferentes modos (visuais, verbais, táteis), fazendo com que a legibilidade da informação seja maximizada, sendo percebida por pessoas com diferentes habilidades (cegos, surdos, analfabetos, entre outros). No que compete à informação e sinalização, na $5^{\underline{a}}$ sessão, reforça-se que as informações devem ser completas, precisas, claras e devem ser dispostas segundo o princípio dos dois sentidos (utilizar mais de uma forma de linguagem), sendo necessário atentar-se para a disposição da informação e da sinalização considerando os seguintes itens: localização, altura, diagramação e contraste.

As informações podem ser disponibilizadas de forma acessível pelos planos e mapas adaptados, que são representações visuais, táteis e/ou sonoras que servem para orientação e localização de lugares, rotas, fenômenos geográficos, cartográficos e espaciais. Estes devem ser construídos de forma a permitir acesso, alcance visual e manual. (ABNT-NBR-9050/15).

Sobre a localização das informações nos espaços públicos, a norma técnica orienta que: a sinalização de identificação deve estar localizada junto à entrada da edificação. Planos ou mapas acessíveis de orientação devem ser instalados, sempre que necessário, imediatamente após a entrada principal das edificações e a sinalização adequada deve ser implantada ao longo do percurso, considerando os pontos de tomada de decisão.

Tendo em vista que é mais fácil a construção de ambientes adaptados do que a posterior adequação destes, Alvarez e Camisão (2014) orientam que, para garantir 
os critérios de acessibilidade devem ser analisados com especial atenção: as condições da pavimentação em geral, desníveis existentes, largura e declividade das calçadas, localização e acesso ao mobiliário urbano, elementos que avancem sobre a área de pedestres, sinalização visual e informativa, semáforos e sinais sonoros, vagas em estacionamentos públicos, situação de acesso, deslocamento e interação aos equipamentos em parques e praças, entre outros.

Outro fator que pode contribuir para a construção de espaços acessíveis é a integração de projetos no ambiente urbano. Essa integração pode ser conseguida, articulando as instituições responsáveis por cada serviço urbano, através de um trabalho coletivo, por exemplo, não colocar lixeiras sobre o piso tátil, não plantar árvores nas calçadas ou rampas que atrapalhem a circulação e, investir na sinalização correta de obras para se evitar acidentes.

Existe uma variedade de normas para a promoção da acessibilidade nos espaços e mobiliários. Convém considerar que ao respeitarem-se os critérios mínimos de acessibilidade garante-se o direito constitucional de todas as pessoas de ir e vir, de acessar as estruturas e apropriar-se dos espaços e respeitando-se estes critérios já no planejamento das obras, pois o ônus é inferior ao bônus de se garantir o acesso a todos.

\section{A acessibilidade no município de Florianópolis/SC}

O Município de Florianópolis, capital do estado de Santa Catarina está localizado sob as coordenadas, 27.59'69" Sul e 48 32' 58" Oeste. Este município possuía no ano de 2019, segundo estimativa do IBGE (2020), uma população de 500.973 habitantes.

O centro urbano de Florianópolis, compreende a área de seu Centro Histórico e seu entorno, onde se concentra a atividade administrativa, os serviços e algumas áreas de turismo e lazer.

O município está sujeito às legislações federais e estaduais, contando com uma lei normativa municipal, destacada anteriormente. As questões de acessibilidade são tratadas dentro da Secretaria Municipal de Meio Ambiente, Planejamento e Desenvolvimento Urbano na qual está inserido o Instituto de Planejamento Urbano de Florianópolis (IPUF). As questões de mobilidade são administradas pela Secretaria Municipal de Mobilidade e Planejamento.

Para avaliar a questão de acessibilidade na área central de Florianópolis, foram definidos locais de serviços e locais de lazer ou turismo. Nestes espaços, 
foram realizadas breves entrevistas com as pessoas responsáveis pelos locais e/ou observação dos espaços, mobiliários, equipamentos urbanos, edificações, transportes, informação e comunicação.

Iniciou-se o campo pelo Terminal de Ônibus Urbano de Florianópolis (TICEN), nele está localizada uma filial da Secretaria Municipal de Mobilidade Urbana, responsável pelas atividades de prestação de serviços de transporte urbano. Nenhum dos funcionários pôde colaborar com a pesquisa, portanto foi realizada apenas observações no terminal. A entrada das pessoas com deficiência no terminal se dá por um portão lateral, onde é vistoriada a carteirinha de gratuidade. Não existe disponibilidade de informações sonora, táteis ou funcionários de serviço assistido, conforme NBR 9060/2015, funcionário para dar apoio, auxiliar qualquer pessoa com dificuldade de circular no ambiente ou de utilizar algum equipamento e dar informações. O que ocorre algumas vezes é o vigilante do terminal auxiliar com informações e na mobilidade de pessoas com deficiência, principalmente visual. $O$ terminal conta com pisos táteis e banheiros adaptados. O acesso ao TICEN, pelas pessoas com deficiência, principalmente visual e física, é um constante desafio, pois não há rota acessível em torno do terminal. Estavam ocorrendo obras de saneamento nas ruas e calçadas, havia buracos ressaltados com cones, madeiras e galhos de árvores. Existem ainda barreiras móveis como vendedores ambulantes sobre as calçadas e vias com carrinhos de lanche, caixas de frutas, roupas e brinquedos. Além, da recorrente modificação da permissão de trânsito de automóveis nas ruas, no entorno ao terminal, fazendo com que o treino para orientação e mobilidade por pessoas com deficiência visual seja prejudicado, os poucos semáforos que contam com informação sonora com acionamento por botoeiras, estão desregulados, podendo colocar os usuários em perigo. Todas essas situações foram observadas nas ruas que dão acesso ao TICEN.

Na sequência da visitação estava a Biblioteca Pública do Estado de Santa Catarina. Em conversa com a diretora, houve a resposta das seguintes questões: $A$ estrutura da biblioteca permite o acesso por pessoas com mobilidade reduzida? Como é realizado o atendimento às pessoas surdas? Há algum acervo disponível para pessoas com deficiência visual? Há algum projeto com o intuito de trazer este público a biblioteca?

Referente à primeira questão, o acesso à biblioteca é feito pela porta principal (Figura 2), onde há uma escadaria sem rampa, o que impossibilita o acesso de pessoas em cadeira de rodas. Há um acesso lateral pelo subsolo, que é utilizado 
para fins de serviços e que poderia ser usado por estas pessoas, contudo, poucos sabem da existência deste acesso. Segundo a diretora não há procura de pessoas em cadeira de rodas pela biblioteca. Isso suscita uma dúvida: até que ponto a escadaria como acesso principal limita este público de usufruir deste serviço? Considerando o exposto pela NBR9060/2015 que as entradas principais de edifícios públicos devem ser acessíveis, faz-se necessário uma adequação urgente.

Dentro do prédio há um elevador que pode ser utilizado por pessoas com mobilidade reduzida, as portas são largas e as mesas têm altura adequada para ser utilizadas por pessoas em cadeiras de rodas, os corredores da biblioteca têm tamanho adequado mínimo de $0,90 \mathrm{~cm}$ e os livros estão em altura adequada ao campo de visão.

Quanto ao atendimento de pessoas surdas, não há nenhum intérprete de LIBRAS e a diretora informou que não saberiam como trabalhar com este público. $O$ atendimento às pessoas com deficiência visual é comum na biblioteca, que conta com um grande acervo de livros e revistas em Braille, variando desde livros didáticos e atlas geográficos até livros de literatura clássica e literatura moderna.

Figura 2 - Entrada da Biblioteca Pública

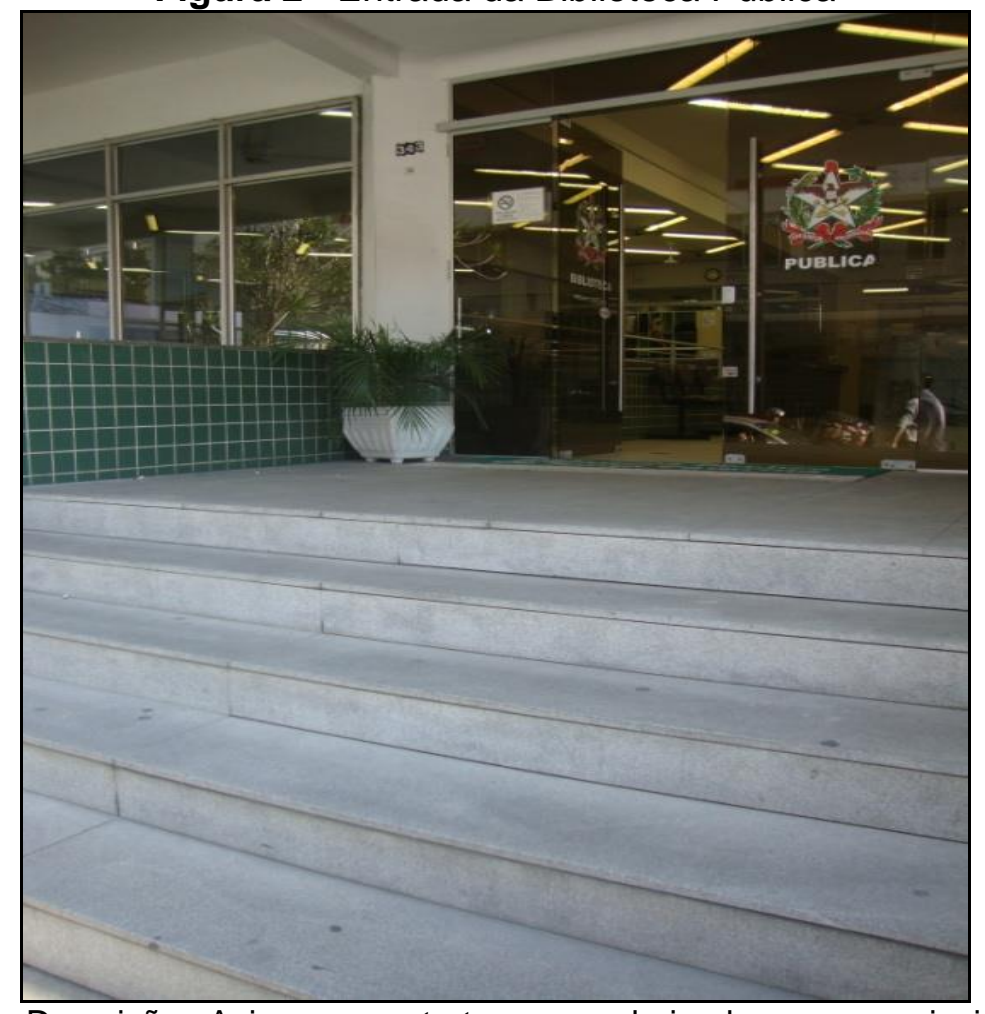

Fonte: Autoras, 2017. Descrição: A imagem retrata a escadaria de acesso principal à Biblioteca Pública de Santa Catarina. 
Quanto à existência de projetos que levem as pessoas com deficiência à biblioteca, a diretora informou que não existem estes projetos, mas se mostra disposta a implantação caso sejam ofertados.

Seguindo na saída a campo foram visitadas duas instituições privadas que ofertam serviços bancários, para entender se há acessibilidade nestes locais. Nestas instituições nenhum funcionário pôde dar informações, então observou-se as estruturas ofertadas. Ambos os locais, as entradas permitem a utilização de andadores ou cadeiras de rodas e existe porta alternativa, àquela giratória que permite entrada de pessoas em cadeiras de rodas.

As duas instituições contam com piso tátil interno (emborrachado, preto), que direciona pessoas com deficiência visual das portas de entrada aos caixas eletrônicos. Esses contam com locais para inserção de fones de ouvido para pessoas com deficiência visual, contudo, não contam com indicadores em Braille. Os painéis para a chamada das senhas são visuais e apresentam informações sonoras (cumprindo com o princípio dos dois sentidos). Uma das instituições apresentava um funcionário para serviço assistido, mas na outra instituição não havia ninguém. A instituição que não tinha funcionário para serviço assistido, contava com um mapa tátil para mobilidade de pessoas com deficiência visual em seu interior.

O Palácio Cruz e Souza foi escolhido por ser um local de turismo e cultura e por estar inserido em uma rota turística que compreende a Praça XV de Novembro e seu entorno histórico, esta construção teve diversas funções. Atualmente, é um museu e apresenta atividades artísticas em seus jardins. Nesta Instituição entrevistou-se a recepcionista acerca das seguintes questões: mobilidade, acervo, atendimento e projetos de inclusão.

Sobre as condições de mobilidade no interior do palácio verificou-se que não é possível receber pessoas com mobilidade reduzida, pois toda a construção é cercada por escadarias. Segundo a entrevistada, os jardins do palácio foram reformados e receberam rampas de acesso, o que permite a utilização do ambiente externo de eventos, por pessoas em cadeiras de roda. Neste caso, por tratar-se de um bem tombado considerado inacessível ou com visitação restrita, a NBR9060 na sessão 10.2 normatiza que, deve-se garantir o acesso por meio de informação visual, auditiva ou tátil das áreas ou dos elementos cuja adaptação seja impraticável, com divulgação das condições de acessibilidade do bem patrimonial informadas com antecedência ao visitante e vinculadas a todo material publicitário. Infelizmente, não se constatou o cumprimento deste quesito. 
Quanto à indagação de como é feito o atendimento de pessoas surdas, obteve-se a resposta que há no museu uma intérprete de LIBRAS, disponibilizada pela Secretaria de Cultura, sendo que esta é a única instituição de cultura que possui uma intérprete. Quanto ao atendimento às pessoas com deficiência visual não sabem como fazê-lo, pois não há obras adaptadas e todo o acervo disponível é visual. Sobre projetos para atender pessoas com deficiência, informou-se que não existem, o museu conta apenas com projetos para atender escolas.

Os outros locais visitados são destinos visados pelos turistas, porém não contam com pessoas que poderiam dar informações, então foi realizada a observação. A Catedral Metropolitana de Florianópolis, localizada próximo à praça $\mathrm{XV}$ de Novembro é destino do turismo religioso e um ponto que se destaca na arquitetura urbana de Florianópolis. A Catedral conta com um dos acessos laterais adaptados, no qual foi implantada uma rampa de metal que leva a uma das portas secundárias que permite o acesso de pessoas com mobilidade reduzida, conforme a Figura 3.

Figura 3 - Catedral metropolitana de Florianópolis

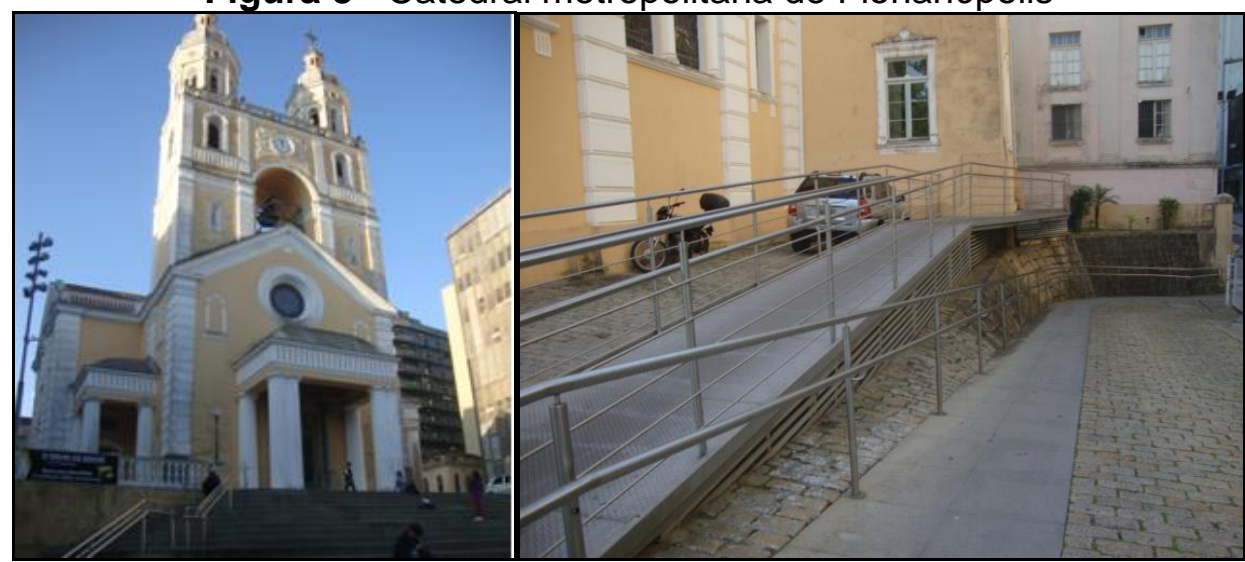

Fonte: Autoras, 2017. Descrição: A figura apresenta duas imagens: a primeira é a Catedral com suas escadarias e a segunda imagem mostra a rampa metálica que foi adaptada no acesso lateral da estrutura.

Dentro da Igreja alguns dos bancos de madeira foram substituídos por cadeiras plásticas que permitem maior mobilidade.

Seguindo com as observações na área central tomou-se como foco a praça XV de Novembro. Observou-se a existência de rampas de acesso para pessoas com mobilidade reduzida, mas não está implantado o piso tátil para tornar essa rota acessível. Os monumentos distribuídos pela praça são de difícil acesso e contam com pequenas placas com informações visuais que já se encontram deterioradas e 
apresentam um padrão de letra pequeno e de difícil leitura. A Praça não conta com nenhuma informação sonora ou mapa tátil e a disposição dos bancos e mesas pode ser um obstáculo à mobilidade de pessoas cegas ou com baixa visão.

Saindo da praça analisou-se o Miramar, localizado próximo ao terminal interurbano de Florianópolis, na Praça Fernando Machado. Anteriormente ele foi um trapiche, bar e restaurante, que após a implantação do aterro da baia sul foi destruído. As colunas do antigo trapiche foram reerguidas como um monumento. $A$ atração não tem tanto destaque turístico, já que a falta de informações sobre ela faz com que passe despercebido em meio ao Centro de Florianópolis. Há um acesso pela lateral da Praça XV de Novembro que a liga ao Miramar, e possui rampas para cadeirantes, piso de alerta e piso tátil direcional que leva até as colunas do antigo Miramar. Nelas encontram-se fixados painéis com informações visuais, porém, não há informação em Braille ou sonora.

Na Secretária Municipal de Mobilidade Urbana (SMMU) conversou-se com a responsável pelas comunicações à imprensa e foram realizados os questionamentos referentes ao transporte público, sendo estes: De que forma pode-se fazer a solicitação de ônibus adaptado e se o serviço tem algum custo? Há algum funcionário para dar suporte às pessoas com deficiência no SETUF e/ou nos terminais urbanos? As informações referentes ao sistema de transportes são adaptadas por exemplo, panfletos, propagandas nas rádios (sonora) e televisão (sonora/visual)? E por fim, há na prefeitura algum órgão que seja responsável pelas questões de acessibilidade?

Sobre o serviço de transporte adaptado, soube-se que ele é gratuito para pessoas com deficiência. Os ônibus adaptados devem ser solicitados junto ao Sindicato das Empresas de Transporte Urbano de Passageiros da Grande Florianópolis (SETUF), sendo que em 2018 havia na frota 454 ônibus adaptados para a utilização de pessoas em cadeiras de rodas. Foi solicitado na implantação da licitação5 de 2014, que todos os ônibus comprados a partir dessa data deveriam ser adaptados, ocorrendo a substituição gradual da frota. Em 2018 apenas 75\% dos ônibus eram adaptados.

Referente ao atendimento às pessoas com deficiência nos postos do SETUF, não há um responsável para auxiliá-los, geralmente os vigilantes assumem este

\footnotetext{
${ }^{5} \mathrm{O}$ conglomerado de empresas de transporte denominado "Consórcio Fênix" ganhou a concessão do transporte público no município por um período de 20 anos e até então, em 2021, não cumpriu com a cláusula de adequação de toda a frota aos critérios de acessibilidade dada pela Lei complementar ํㅡ 590, de 06 de dezembro de 2016 (FLORIANÓPOLIS, 2016).
} 
papel, assim como no auxílio das pessoas com deficiência para mobilidade dentro dos terminais urbanos. As campanhas publicitárias e informações referentes ao sistema de transporte não são disponibilizadas em formatos adaptados: Braille e LIBRAS.

A entrevistada também afirmou que não há um órgão específico para assuntos de acessibilidade sendo que há pessoas que trabalham nesta área dentro das distintas secretarias do município.

Esta última entrevista aconteceu na sede da prefeitura de Florianópolis localizada na Rua Conselheiro Mafra oㅜ 656. Embora o prédio apresente todos os critérios de acessibilidade, pisos táteis, rampas, portas largas, elevadores, banheiros adaptados, considerando o deslocamento do terminal de ônibus até este local, verificou-se que a mobilidade se apresenta seriamente comprometida devido a inúmeros obstáculos sobre as calçadas, os pisos táteis de alerta estão deteriorados, há obras e buracos no caminho que tornam- se empecilhos ao acesso de todos, conforme mostra a Figura 4.

Figura 4 - Obstáculos sobre as calçadas

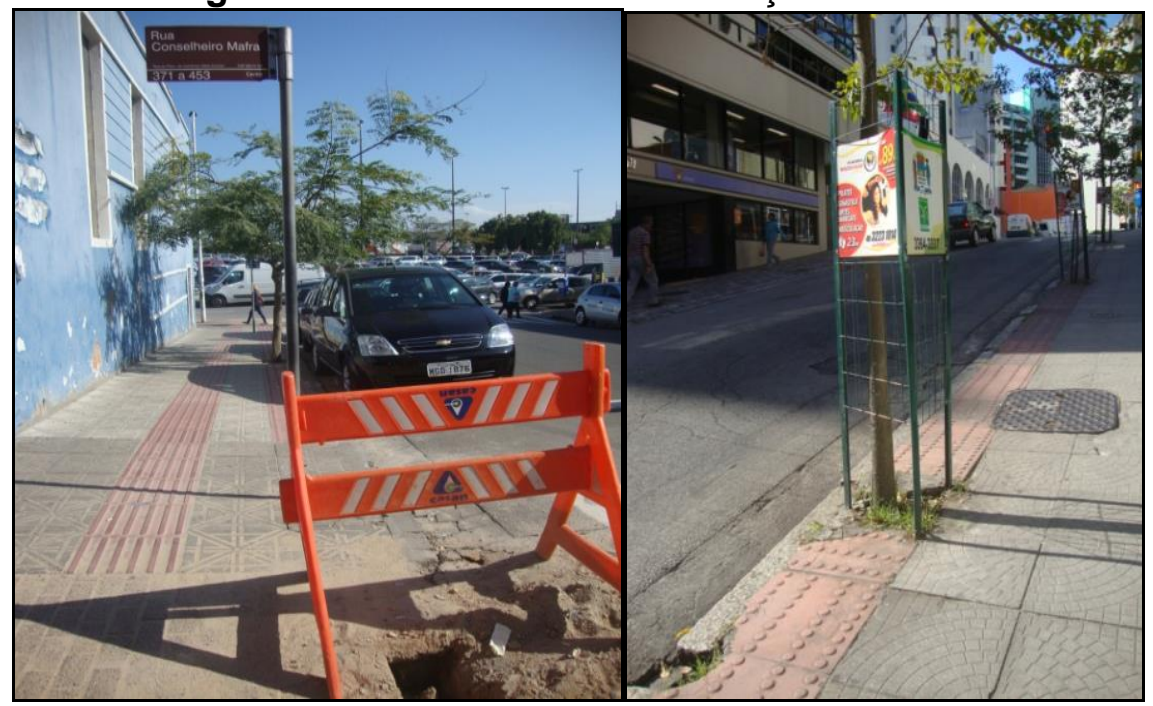

Fonte: as autoras, 2017. Descrição: A figura apresenta duas imagens a primeira mostra um buraco feito pela CASAN sob a rampa e a faixa de pedestres na Rua Conselheiro Mafra. A segunda imagem mostra uma árvore com um cartaz de propaganda afixada sobre o piso tátil de alerta, pode-se perceber o deterioramento do piso.

Acerca das obras, eventualmente existentes sobre o passeio, a NBR 9060/2015 aponta que estas devem ser convenientemente sinalizadas e isoladas, assegurando-se a largura mínima de $1,20 \mathrm{~m}$ para circulação, garantindo-se as condições de acesso e segurança, o que não acontece já que a obra estava sobre a faixa de pedestre e rampa. 
O último local analisado, foi o tradicional Mercado Público de Florianópolis, construído em 1898, em substituição a um antigo mercado, que ali existiu por 45 anos, até ser demolido em 1896. Esse Mercado foi reformado e conforme observouse procurou atender o Art. 10 da Lei ํo 7801, o qual discorre que a construção, reforma ou ampliação de edificações de uso público ou coletivo, deverão ser executadas de modo que sejam ou se tornem acessíveis à pessoa com deficiência ou com mobilidade reduzida. O Mercado apresenta duas alas (Norte e Sul) com um espaço adequado para a mobilidade de cadeirantes. Ganhou pisos táteis de alerta e direcional e as rampas foram consertadas. Todavia, como os outros espaços públicos externos observados, não conta com informações adaptadas nem serviço assistido. Esta estrutura arquitetônica foi toda reformada com critérios de acessibilidade inclusive seu vão central, ver Figura 5. Entretanto, pode-se observar na imagem que o piso tátil direcional não contrasta visualmente com o pavimento da calçada (os dois de cor cinza), com isto, percebe-se que não está adequado para as pessoas com baixa visão, fato que poderia ser evitado, se empregado a coloração adequada na reforma.

Considerando a legislação, constatou-se que o Mercado Público após a reforma foi adaptado, pois teve suas características arquitetônicas originais alteradas para propiciar a acessibilidade, todavia ainda não é completamente acessível, havendo para isto, a necessidade de adequar a coloração de cinza para preta (cor padrão estabelecida no município) do piso tátil direcional e disponibilizar informações de forma acessível.

Figura 5 - Mercado Público de Florianópolis

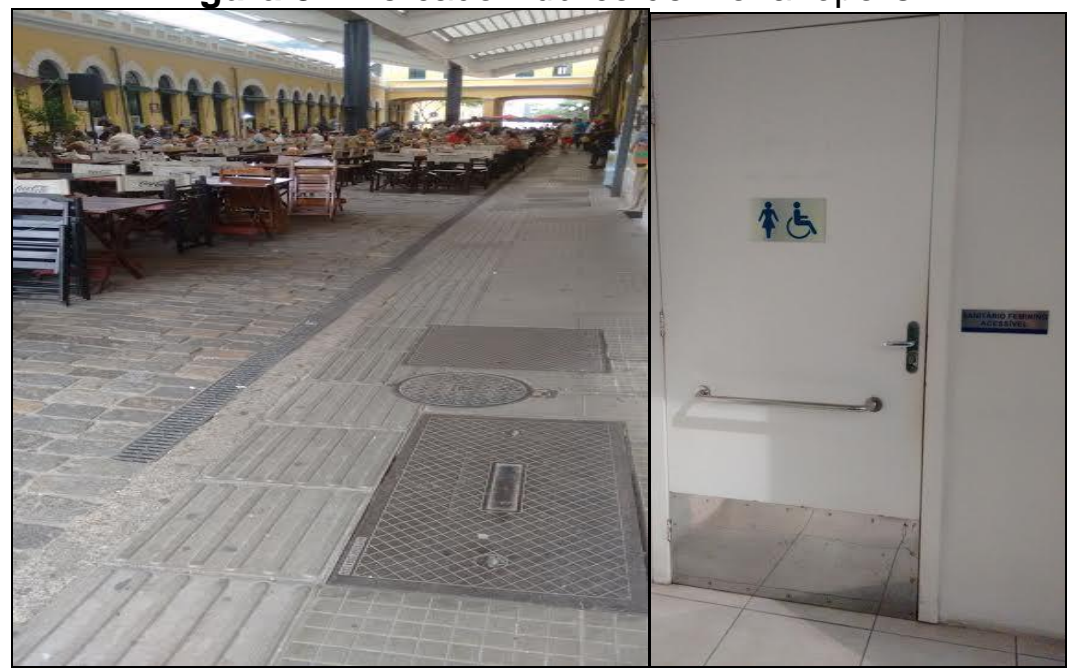

Fonte: as autoras, 2017. Descrição. 5A. Destaque para a calçada com piso tátil direcional no vão central do Mercado público, ao fundo há mesas e portas que dão acesso as lojas. 5b. Porta de banheiro adaptado dentro da Ala Sul, com puxador na altura da cadeira de rodas e placa em Braille ao lado da maçaneta. 
Percebe-se uma tentativa de adequação às leis de acessibilidade por parte do município, nas reformas recentes dos espaços públicos. Constatou-se que através de pequenas alterações estruturais pôde-se dar acesso às pessoas com deficiência a espaços, até então inalcançáveis.

A existência de leis que regulamentem a acessibilidade é um grande avanço do Movimento Social das Pessoas com Deficiência. Entretanto, a existência delas desvinculada de uma política pública que cobre a implantação, fiscalize as estruturas e avalie os serviços ofertados, faz com que a verdadeira inclusão das pessoas com deficiência no meio social se torne apenas "oficial" e não "real".

\section{Considerações Finais}

Os documentos normativos nacionais e internacionais, desde a Declaração Universal dos Direitos Humanos (1948) até a Lei Brasileira de Inclusão da Pessoa com Deficiência (2015) estabeleceram que deve existir igualdade de condições para todas as pessoas no acesso à cidade, todavia estes dispositivos estão aquém das necessidades ou não se concretizaram quando nos referimos ao Direito à cidade das chamadas minorias, entre elas as pessoas com deficiência e outros grupos marginalizados.

A materialização dos direitos, não se dá de forma equitativa a todos os habitantes, mas numa lógica social que tem sido reproduzida de modo a naturalizar as condições sociais de desigualdade e de segregação. O fato destacado, evidenciou-se com as saídas a campo. Nelas pôde-se observar que o cumprimento à legislação de acessibilidade em Florianópolis está ainda aquém do desejado e de um modo geral, esta falta de acessibilidade é percebida de forma naturalizada.

As estruturas que promovem a acessibilidade são pontuais, como o acervo disponibilizado em Braille na Biblioteca Pública, considerando que a cultura de conhecimento acessível ainda é incipiente no Brasil. As adaptações para mobilidade na Catedral Metropolitana, sendo que o público que usufruí deste espaço, em grande parte é da terceira idade, que necessita de auxílio para a locomoção e as reformas do Mercado Público, que adequou sua estrutura as leis de acessibilidade.

Em muitos locais a acessibilidade ainda não é uma realidade, entre estes está o acesso principal da Biblioteca Pública, que fere todas as legislações no que condiz aos critérios de mobilidade e do direito de usufruir dos espaços públicos, podendo ser convertido até mesmo em segregação. Tal observação é decorrente do fato de as pessoas com dificuldade de mobilidade terem que acessar este espaço por uma 
entrada de serviços no subsolo, sendo que não há menção da existência dela em nenhum lugar.

Outro ponto que destoa negativamente é a dificuldade de acesso à cultura, às informações e conhecimentos, sendo este um fator que prejudica imensamente as pessoas com deficiência sensorial, pois nenhuma informação nos locais visitados é projetada para estas pessoas. Sendo que por lei os espaços de uso público deveriam ter disponibilizadas informações de forma acessível. Para atender a esta necessidade, poderiam ser importadas experiências positivas de alguns países como França, Portugal e Itália, onde além dos critérios de acessibilidade para mobilidade, estão sendo implantadas nos locais turísticos, informações sonoras, painéis informativos, placas com textos em Braille e mapas táteis que permitem aos usuários o acesso à informação, audiodescrição entre outras tecnologias assistivas que propiciam o acesso a todos.

Um fato curioso no tocante à acessibilidade nos locais visitados é que não há um comprometimento em respeitar as próprias obras de acessibilidade já executadas. As estruturas de acessibilidade são implantadas sem o entendimento de que elas precisam estar desobstruídas e que precisam de manutenção e fiscalização, como preconiza a própria legislação. Verificou-se em campo, que há barreiras colocadas sobre o piso tátil e, falta manutenção das calçadas e rampas de acesso. Também convém destacar que, não ocorre uma integração entre os organismos públicos prestadores de serviço em considerar os critérios de acessibilidade como fundamentais, sendo as intervenções de acessibilidade, majoritariamente, realizadas de forma isolada e pontual.

Tendo em vista as questões observadas, constata-se que acessar o Centro da cidade de Florianópolis, sem tutela é um desafio constante, principalmente para as pessoas com deficiência visual e para pessoas com deficiência física, fato que pode se converter em uma privação do direito constitucional de ir e vir por ausência de mecanismos de acessibilidade. Sendo que é injusto atribuir incapacidades ou deficiências às pessoas quando os maiores empecilhos lhes são conferidos pelo meio social.

Desta forma, quanto mais a pessoa com deficiência estiver num ambiente que Ihe restrinja a mobilidade, a comunicação, o acesso à informação e aos bens sociais para uma vida plena e autônoma, vai encontrar-se numa situação de desvantagem. O desafio atual é organizar o planejamento urbano para garantir uma sociedade para todos, pois se observados os critérios do desenho universal não apenas as 
pessoas com deficiência irão se beneficiar. O acesso à cidade será facilitado para as pessoas temporariamente com mobilidade reduzida, para gestantes, crianças e idosos.

As discussões sobre acessibilidade devem romper o marco legislativo e se manifestar nas lutas sociais pelo direito à uma cidade para todos. Em contribuição a isto, este trabalho, tal qual Lefebvre (1991, p. 9) "deseja romper os sistemas não para substituí-los por outro sistema, mas para abrir o pensamento e a ação na direção de possibilidades que mostrem novos horizontes e caminhos".

\section{REFERÊNCIAS}

ALVAREZ, Eduardo; CAMISÃO, Verônica. Guia operacional de acessibilidade [do Banco Interamericano de Desenvolvimento - BID] para projetos de desenvolvimento urbano com critérios de desenho universal. Rio de Janeiro: José Brakarz e Tomás Engles (Ed.), 2014.

ASSOCIAÇÃO BRASILEIRA DE NORMAS TÉCNICAS. NBR 9050: Acessibilidade a edificações, mobiliário, espaços e equipamentos urbanos. Rio de Janeiro, 2015.

BRASIL. Decreto № 6.949, de 25 de agosto de 2009. Disponível em:

http://www.planalto.gov.br/ccivil 03/ Ato2007-2010/2009/Decreto/D6949.htm. Acesso em: 20 mai. 2020.

BRASIL. Lei n. 13.146, de 6 de jul. de 2015. Lei Brasileira de Inclusão da Pessoa com Deficiência. Disponível em: http://www.planalto.gov.br/ccivil 03/ Ato2015-

2018/2015/Lei/L13146.htm; Acesso em: 20 mai. 2020.

FIGUEIREDO, Paulo Cesar dos Santos. Alterações na nova NBR 9050, de 11/10/2015. Disponível em: https://www.riscobiologico.org/. Acesso em 5 mai. 2020.

FÓRUM SOCIAL MUNDIAL POLICÊNTRICO. Carta Mundial pelo Direito à Cidade. 2006. Disponível em: http://www.unhabitat.org/ Acesso em 5 jun. 2020.

FLORIANÓPOLIS. Lei Ordinária № 7801, de 30 de dezembro de 2008. Disponível em: https://cm.jusbrasil.com.br/legislacao/982145/lei-7801-08. Acesso em 5 jun. 2020.

FLORIANÓPOLIS. Lei complementar no 590, de 06 de dezembro de 2016. Disponível em: https://leismunicipais.com.br/a/sc/f/florianopolis/lei-complementar/2016/59/590/leicomplementar-n-590-2016-altera-dispositivos-da-lei-n-7801-de-2008. Acesso em 5 jun. 2020.

FLORIANÓPOLIS. Instituto de Planejamento Urbano. Cadernos de Planejamento e Projetos Urbanos de Florianópolis. Disponível em:http://www.pmf.sc.gov.br/arquivos/arquivos/pdf/02 102019 15.09.05.2943a273527a07 ace38562f47c9276e1.pdf. Acesso em: 20 mai. 2020.

IBGE (Instituto Brasileiro de Geografia e Estatística). População estimada do município de Florianópolis. Disponível em:

https://cidades.ibge.gov.br/brasil/sc/florianopolis/panorama. Acesso em: 20 mai. 2020. 
LABTATE. Mapas táteis. Disponível em: http://www.labtate.ufsc.br/. Acesso em 5 jun. 2020

LEFEBVRE, Henri. O Direito à Cidade. 1ํㅡㄹ ed. São Paulo: Moraes, 1991.

ORGANIZAÇÃO DAS NAÇÕES UNIDAS (ONU). Declaração Universal dos Direitos Humanos. Adotada e proclamada pela resolução 217 A (III) da Assembleia Geral das Nações Unidas em 10 de dezembro de 1948. Disponível em:

http://portal.mj.gov.br/sedh/ct/legis intern/ddh bib inter universal.htm. Acesso em: 20 mai. 2020.

ORGANIZAÇÃO DAS NAÇÕES UNIDAS (ONU). Convenção sobre os direitos das pessoas com deficiência. Disponível em:

https://www.un.org/development/desa/disabilities/convention-on-the-rights-of-persons-withdisabilities.html. Acesso em: 20 mai. 2020.

\section{NOTAS DE AUTOR}

\section{CONTRIBUIÇÃO DE AUTORIA}

Tamara de Castro Régis - Concepção. Coleta de dados, Análise de dados, Elaboração do manuscrito, revisão e aprovação da versão final do trabalho

Ruth Emilia Nogueira-Participação ativa da discussão dos resultados; Revisão e aprovação da versão final do trabalho.

\section{FINANCIAMENTO}

O presente trabalho foi realizado com apoio da Coordenação de Aperfeiçoamento de Pessoal de Nível Superior Brasil (CAPES) - Código de Financiamento 001.

\section{CONSENTIMENTO DE USO DE IMAGEM}

Não se aplica.

\section{APROVAÇÃO DE COMITÊ DE ÉTICA EM PESQUISA}

Não se aplica.

\section{CONFLITO DE INTERESSES}

Não há conflitos de interesse.

\section{LICENÇA DE USO}

Este artigo está licenciado sob a Licença Creative Commons CC-BY. Com essa licença você pode compartilhar, adaptar, criar para qualquer fim, desde que atribua a autoria da obra.

\section{HISTÓRICO}

Recebido em: 26-04-2017

Aprovado em: 05-10-2020 